\title{
DIFFERENT PROTEIN PROFILES IN INFERIOR COLLICULUS AND CEREBELLUM: A COMPARATIVE PROTEOMIC STUDY
}

\author{
M. BECKER, H. G. NOTHWANG AND E. FRIAUF* \\ Abteilung Tierphysiologie, Fachbereich Biologie, Technische Univer- \\ sität Kaiserslautern, Postfach 3049, 67653 Kaiserslautern, Germany
}

\begin{abstract}
The characteristic features of individual brain regions are determined by anatomical, physiological, and biochemical properties, which are caused by the nature and amount of proteins expressed. Proteomics is a powerful technology for assessing different protein profiles, comparing hundreds of proteins simultaneously. Here we performed a semi-quantitative proteomic analysis of two prominent brain regions in the male adult rat, the inferior colliculus and the cerebellum. Both play important roles in sensorimotor integration but have distinct anatomical and biochemical features. Soluble proteins of mainly cytoplasmic origin were obtained through subcellular fractionation, separated by twodimensional gel electrophoresis, and identified by matrixassisted laser desorption/ionization mass spectrometry. Out of 169 annotated and quantified spots, $40(24 \%)$ displayed significant differences in intensity between the two brain regions. Of those, 21 spots (containing 26 proteins) were more intense in the inferior colliculus and 19 spots (containing 25 proteins) in the cerebellum. The inferior colliculus displayed a higher abundance of proteins involved in vesicular trafficking, such as dynamin-1 and cofilin-1. In the cerebellum, $\mathrm{Ca}^{2+}$-binding proteins (calbindin and calretinin) as well as 14-3-3 proteins were more abundant. Both protein groups play a central role in cellular signaling. Finally, several differences occurred among proteins involved in cellular energy metabolism. Our study presents a proof of principle to demonstrate marked heterogeneity of proteins between two brain samples. The heterogeneity is likely associated with functional differences, warranting further histological and physiological analyses. (c) 2008 IBRO. Published by Elsevier Ltd. All rights reserved.
\end{abstract}

Key words: brain proteomics, gel-image analysis, two-dimensional gel electrophoresis, region-specific differences, mass spectrometry.

The mammalian brain, arguably the most complex organ known, consists of a plethora of heterogeneous regions that differ from each other in anatomical, physiological, and biochemical properties (Becker et al., 2006). These properties are derived from both qualitative and quantitative differences in the protein pattern. For assessing differential protein expression, proteomics is a powerful tool. The

*Corresponding author. Tel: +49-631-205-2424; fax: +49-631-205-4684. E-mail address: eckhard.friauf@biologie.uni-kl.de (E. Friauf).

Abbreviations: AF, abundance factor; IC, inferior colliculus; MALDI, matrix-assisted laser desorption/ionization; MS, mass spectrometry; RuBP, Ruthenium II tris bathophenantrolinedisulfonate; SDS-PAGE, sodium dodecyl sulfate polyacrylamide gel electrophoresis. major difference to previously existing analytical techniques (e.g. immunochemistry) is that proteomics does not analyze proteins individually, but on a highly automated, large-scale level, thus allowing the simultaneous comparison of hundreds of different proteins.

Several neuroproteomics studies have analyzed the brain as a whole or were aimed at identifying differences between health and disease (Cheon et al., 2001; Zheng et al., 2003; Kim et al., 2004), age-related differences (Chen et al., 2003b), or changes caused by traumata (Denslow et al., 2003). Our strategy complements these approaches by comparing specific brain regions from healthy animals. In the present study, we analyzed the expression profiles of proteins in the inferior colliculus (IC) and the cerebellum of male adult rats. The IC is an obligatory relay station in the auditory system and participates in the temporal integration of sound and in the construction of an initial auditory image used for reflexive behavior (Casseday and Covey, 1996; Davis et al., 2003). The cerebellum controls the timing of coordinated, skilled movements of skeletal muscles, integrating inputs from various brain regions as well as the spinal cord (Thach and Bastian, 2004; Ito, 2005). Degeneration or loss of cells in the cerebellum leads to unsteadiness of gait, miscoordination of movement, and ataxia (Gilman, 2000). Thus, both regions are involved in sensorimotor integration, guiding appropriate motor responses, albeit in different context.

Our comparative proteomics study was designed as a proof of principle study to assess whether distinct, but presumably small, differences between two brain regions can be resolved. Combining two-dimensional gel electrophoresis, quantification with specialized software, and matrix-assisted laser desorption/ionization (MALDI) -mass spectrometry (MS) based protein identification, we elucidated a series of proteins with different, i.e. region-specific expression levels. This demonstrates that an analysis of individual brain regions is feasible by gel-based proteomics. It is a useful approach to analyze developmental processes or disease models, where changes may be brainregion specific.

\section{EXPERIMENTAL PROCEDURES}

\section{Reagents}

Acrylamide and other reagents for polyacrylamide gel electrophoresis, as well as most other chemicals, were obtained from Roth (Karlsruhe, Germany). SB3-10 was supplied by Sigma (Munich, Germany) and the protease inhibitor cocktail by Roche (Mannheim, Germany).

0306-4522/08 $\$ 32.00+0.00$ @ 2008 IBRO. Published by Elsevier Ltd. All rights reserved.

doi:10.1016/j.neuroscience.2008.02.017 


\section{Animals and preparation}

Young adult male Sprague-Dawley rats (8-9 weeks old) were obtained from Charles River Laboratories (Sulzfeld, Germany) and kept $48 \mathrm{~h}$ in our local facilities for acclimatization. Animals were deeply anesthetized by a peritoneal injection of $700 \mathrm{mg} / \mathrm{kg}$ chloral hydrate and killed by decapitation. Protocols were approved by the responsible animal care and use committee (Landesuntersuchungsamt Rheinland-Pfalz, Koblenz, Germany) and adhered to the NIH Guide for the Care and Use of Laboratory Animals. All efforts were made to minimize the number of animals and their suffering. After removal of the brain from the skull, the cerebellum was separated from the underlying brainstem by cutting horizontally through its pedunculi (Fig. 1a). The cortical hemispheres were separated by cutting along the midline, thus exposing the colliculi (Fig. 1b). The ICs were separated from the superior colliculi and the underlying tegmental brainstem (Fig. 1c). Cerebellum and ICs were prepared conservatively to avoid contamination by surrounding brain regions (Fig. 1d). The tissue samples were collected from single individuals and kept separated for the generation of biological replicates. They were immediately frozen in liquid nitrogen and stored at $-80^{\circ} \mathrm{C}$.

\section{Sample preparation}

To focus on soluble, predominantly cytoplasmic proteins, the tissue samples were subjected to subcellular fractionation as described previously (Guillemin et al., 2005). In brief, frozen tissue was transferred to lysis buffer ( $10 \mathrm{mM}$ Hepes, $10 \mathrm{mM} \mathrm{NaCl}, 1 \mathrm{mM}$ $\mathrm{KH}_{2} \mathrm{PO}_{4}, 5 \mathrm{mM} \mathrm{NaHCO}$, $5 \mathrm{mM}$ EDTA, $1 \mathrm{mM} \mathrm{CaCl}, 0.5 \mathrm{mM}$ $\mathrm{MgCl}_{2}, \mathrm{pH} 7.5$ ), and pre-homogenized by two strokes in a Teflon/ glass homogenizer. The suspension was incubated in lysis buffer on ice for $10 \mathrm{~min}$, followed by six strokes of a motorized homogenizer. Thereafter, isotonic conditions were restored with 0.1 volume of $2.5 \mathrm{M}$ sucrose. Differential centrifugation was performed, starting with an initial centrifugation step at $6300 \times \mathrm{g}$ for $10 \mathrm{~min}$ to sediment nuclei and cell debris. The supernatant from the first
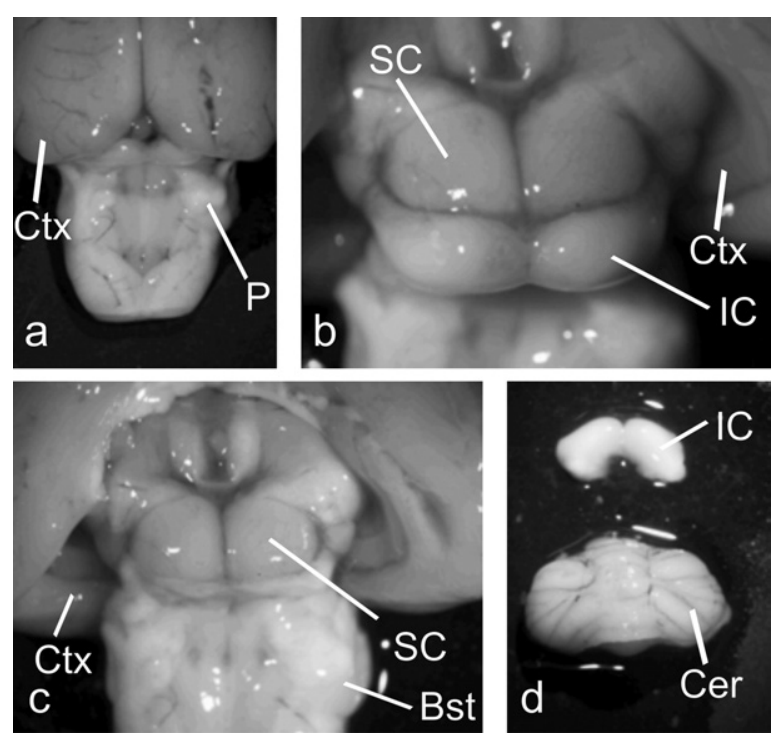

Fig. 1. Preparation of the two rat brain regions. (a) After removing the brain from the skull, the cerebellum was isolated by cutting horizontally through its pedunculi $(\mathrm{P})$. (b) The cortical hemispheres (Ctx) were separated by cutting along the midline, revealing the colliculi below. (c) The IC were separated from the superior colliculi (SC) and the underlying tegmental brainstem (Bst). (d) Cerebellum and IC were prepared conservatively to minimize contamination by surrounding brain regions. round of centrifugation was subjected to a prolonged centrifugation step $(107,000 \times g$ for $30 \mathrm{~min})$. The resulting supernatant was cleaned up by precipitation with trichloroacetic acid (40\%), subsequently washed with acetone $(80 \%)$, and resuspended in rehydration buffer (5 M urea, $2 \mathrm{M}$ thiourea, 2\% CHAPS, 2\% SB 3-10 and $40 \mathrm{mM}$ Tris) prior to two-dimensional gel electrophoresis. Protein concentration was determined by densitometry, comparing a sample aliquot with a dilution series of a protein standard after separation by sodium dodecyl sulfate polyacrylamide gel electrophoresis (SDS-PAGE).

\section{Two-dimensional gel electrophoresis}

In order to separate proteins in the first dimension, 18-cm-long immobilized pH-gradient strips (ReadyStrip IPG-strip, pH 3-10, BioRad, Munich, Germany) were used following the manufacturer's instructions. After rehydration (12 h), isoelectric focusing was performed $(33,000 \mathrm{Vh})$ on an IPGphor isoelectric focusing unit (GE Healthcare). After equilibration, the gel strips were transferred to a $12 \%$ SDS-PAGE for the second dimension, using a Protean II xi cell (25 mA for $6 \mathrm{~h}$, Bio-Rad).

Both analytical and preparative gels were prepared. Analytical gels were loaded with $\sim 25 \mu \mathrm{g}$ of protein sample and stained with Ruthenium II tris bathophenantrolinedisulfonate (RuBP), a highly sensitive dye that stains linearly across a large dynamic range (Berggren et al., 2000; Lamanda et al., 2004). Gel images were acquired with a Versadoc 3000 imaging system (Bio-Rad). Preparative gels were loaded with $\sim 500 \mu \mathrm{g}$ of protein sample and stained with colloidal Coomassie Blue G250 (17\% ammonium sulfate, $34 \%$ methanol, $0,5 \%$ acetic acid, $0,1 \%$ Coomassie Blue G250). Gel images were acquired using a gel scanner (GS-800 calibrated densitometer, Bio-Rad).

\section{Protein identification by MS}

Protein spots were excised from preparative gels using a spot cutter (ProteomeWorks plus Spot Cutter, Bio-Rad). Excised spots were washed first with $50 \mathrm{mM} \mathrm{NH}_{4} \mathrm{HCO}_{3}$ and then with $50 \%$ acetonitrile/25 mM NH $\mathrm{mHCO}_{3}$. Protein disulfides were reduced with $10 \mathrm{mM}$ DTT at $56{ }^{\circ} \mathrm{C}$ for $30 \mathrm{~min}$, followed by carbamidomethylation with $5 \mathrm{mM}$ iodoacetamide for $30 \mathrm{~min}$. Finally, the spots were washed again as described above and dried. Proteins were in-gel digested overnight at $37^{\circ} \mathrm{C}$ by adding $3 \mu \mathrm{l}$ of $0.6 \%(\mathrm{w} / \mathrm{v})$ trypsin (Promega, Madison, MA, USA) in $50 \mathrm{mM} \mathrm{NH}_{4} \mathrm{HCO}_{3}$. Peptides were extracted by incubating them with $0.1 \%$ trifluoroacetic acid for $45 \mathrm{~min}$, then concentrated using PerfectPure C-18 tips (Eppendorf, Hamburg, Germany), and finally eluted onto a MALDI target plate (MTP AnchorChip 384/600, Bruker Daltonics, Bremen, Germany), using $\alpha$-cyano-4-hydroxycinnamic acid as matrix.

Spectra were acquired using a MALDI-TOF-TOF (time-offlight) instrument (Ultraflex, Bruker Daltonics) operating in reflector mode with the reflector voltage set to $25 \mathrm{kV}$. External calibration of the instrument was based on spectra obtained from a mixture of nine standard peptides (Peptide Calibration Standard II, Bruker Daltonics). One-thousand spectra per sample were summed up and processed with FlexAnalysis 2.2 (Bruker Daltonics) to generate a mass list. Internal calibration was achieved using trypsin autoproteolytic fragments present in the spectra. Peptide mass fingerprints were analyzed with Biotools 2.2 (Bruker Daltonics). MASCOT searches were conducted considering carbamidomethylation and oxidation of methionine as variable modifications. Peptide mass tolerance was set at $0.15 \mathrm{Da}$. Initial searches were performed using the Swissprot database limited to entries for Rattus norvegicus. If no significant hits (molecular weight search (Mowse) score of $>50 ; P>0.05$ ) were obtained on initial searches, the database size was increased to include all mammalian entries from the NCBI non-redundant database NCBInr. In case of significant hits, matching peptides were removed from the mass list and 
second pass searches were performed to identify additional proteins in the sample.

\section{Gel image analysis}

RuBP-stained analytical gels were evaluated using a specialized software tool (Proteomweaver 3.0, Bio-Rad). Gel images (three biological replicate gels each for cerebellum and IC) were converted to 16 bit grey-scale images in TIFF format. After cropping, spot detection was performed using the built-in spot detection wizard. Radius, intensity, and contrast limits were initially set to 3 , 1000 , and 14, respectively, and slightly adjusted thereafter. After spot detection, individual spot sets were manually checked to remove artifacts and to correct merged or split spots. Each gel was pair-matched with all other gels in an experiment, and multimatching was conducted using standard settings. Normalization of spot intensities was performed in two steps, using the standard procedure provided by the software. First, spot intensities were converted to an arbitrary scale, applying a normalization point of $95 \%$ and a pre-match normalization factor of 1 . Second, a normalization factor was determined for each pair of gels, assuming that at least $50 \%$ of all spots had equal intensities. From these factors, an optimal normalization factor was determined and applied to all spot intensity values. All spots analyzed were assigned to one of three categories. Spots that appeared on two to three gels in one group, but on less than two gels in the reference group, were considered 'exclusive spots' and assigned an abundance factor (AF) of ' $\infty$.' All exclusive spots were subjected to manual revision to exclude artifacts. Spots which were detected on two or three gels in both groups analyzed were defined as 'major spots.' For all major spots, AFs (the geometric mean of spot intensities from one group, divided by the geometric mean of spot intensities from the reference group) were calculated. To check for significant intensity differences between major spots in either cerebellum or IC, log-intensities were subjected to a Student's $t$-test $(P \leq 0.05$ or $P \leq 0.01)$. Spots appearing in less than two gels in both groups were termed 'nonspots' and excluded from further analysis.

\section{Western blotting}

Experiments were essentially performed as described previously (Blaesse et al., 2006) and slightly modified. Proteins were obtained from the cytosolic fraction of the IC or the cerebellum of P60 rats, and equal amounts $(20-40 \mu \mathrm{g})$ were separated by $8-12 \%$ SDS-PAGE. Electrophoretic separation was performed with $25 \mathrm{~mA}$ for 1-1.5 h. Proteins were electrophoretically transferred to polyvinylidene difluoride membranes (Roth), and membranes were incubated in TTBS/milk. After a blocking reaction for 15 $\mathrm{min}$, the respective antiserum was added and incubation was done overnight at $7{ }^{\circ} \mathrm{C}$, followed by $2 \mathrm{~h}$ at room temperature. The following primary antibodies and dilutions were used: anticalbindin mouse monoclonal antibody, clone C8666 (Sigma, Taufkirchen, Germany) at 1:1000; anti-calretinin rabbit polyclonal antibody, clone 6B3 (Swant, Bellinzona, Switzerland) at 1:2000, anti-14-3-3 gamma mouse monoclonal antibody, clone CG31-2B6 (Upstate Biotechnology, Lake Placid, NY, USA) at 1:5000, anti-dynamin 1 rabbit polyclonal antibody, clone 55397 (Abcam, Cambridge, UK) at 1:500, and n-cofilin rabbit polyclonal antibody (clone KG-60, kind gift from Christine B. Gurniak, European Molecular Biology Laboratory, Mouse Biology Unit, Monterotondo, Italy) at 1:1000. The secondary antibodies were goat anti-mouse or anti rabbit IgG-HRP (Amersham Biosciences, Freiburg, Germany) and applied at 1:5000 for $1 \mathrm{~h}$ at room temperature in TTBS/milk. After thorough washes, the blots were developed using Western Lighting Chemiluminescence Reagent Plus (Perkin Elmer, Waltham, MA, USA) and detected using a VersaDoc 3000 documentation system (BioRad).

\section{RESULTS}

\section{Protein maps for IC and cerebellum}

To generate an overview of the protein complement of the IC and the cerebellum, we prepared Coomassie-stained preparative gels for each of the two brain regions and annotated excised protein spots by MALDI-MS analysis. Our analysis focused on soluble, mainly cytoplasmic proteins which we obtained by differential centrifugation (Guillemin et al., 2005).

We annotated a total of 169 spots (Fig. 2). Because co-migrating proteins were present in $25 \%$ of the spots, we obtained a total of 220 annotations (Supplemental Table 1). We identified two proteins in 34 spots, three proteins in seven spots and four proteins in one spot (Fig. 3a). Because many proteins were identified in up to seven spots (e.g. creatine kinase, B chain, Fig. 1, spots $43,52-55,67$, 94), the 220 annotations corresponded to 117 different genes (Fig. 3b).

We identified enzymes involved in energy metabolism (e.g. malate dehydrogenase, pyruvate dehydrogenase), elements of the cytoskeleton (e.g. tubulin alpha and beta chains), and other housekeeping molecules (e.g. carbonic anhydrase II, heat shock cognate $71 \mathrm{kDa}$ protein). The neural (i.e. neuronal and/or glial) origin of the sample tissues was well reflected by the presence of several brainspecific proteins (e.g. glial fibrillary acidic protein, myelin basic protein $S$, neurofilaments) and brain-specific isoforms of housekeeping enzymes (e.g. creatine kinase Btype, gamma enolase). Because of the essential role of such proteins in all brain regions, the vast majority of the spots $(>90 \%)$ were detected on gels loaded with either cerebellum or IC samples. This observation also held true for gels loaded with proteins from various other brain preparations, such as superior olivary complex, whole brainstem, or total brain (data not shown). As a consequence, the annotated map of cerebellar proteins that we present can be used as a general reference for IC gels and others (Fig. 2). It should be noted, though, that the qualitative similarities between two samples do not indicate that there are no differences between the samples. Rather, such differences are likely to be reflected on a quantitative level, displaying changes in the abundance of ubiquitous proteins.

\section{Differential analysis of IC and cerebellum proteomes}

To screen for quantitative differences between the proteome of the IC and that of the cerebellum, we prepared three RuBP-stained analytical gels of each region. For each gel, we used tissue samples from male rats, thereby ruling out effects of gender differences. We analyzed three independent biological replicates, each based on tissue from an individual animal. For the quantitative analysis, all 169 annotated spots from the Coomassie-stained preparative gels were assigned to one of three groups based on their frequency on the replicate gels (see Experimental Procedures).

The first group comprised spots that were detected on at least two replicate gels for one brain region, but on less 
$10^{-3} \times \mathrm{Mr}$

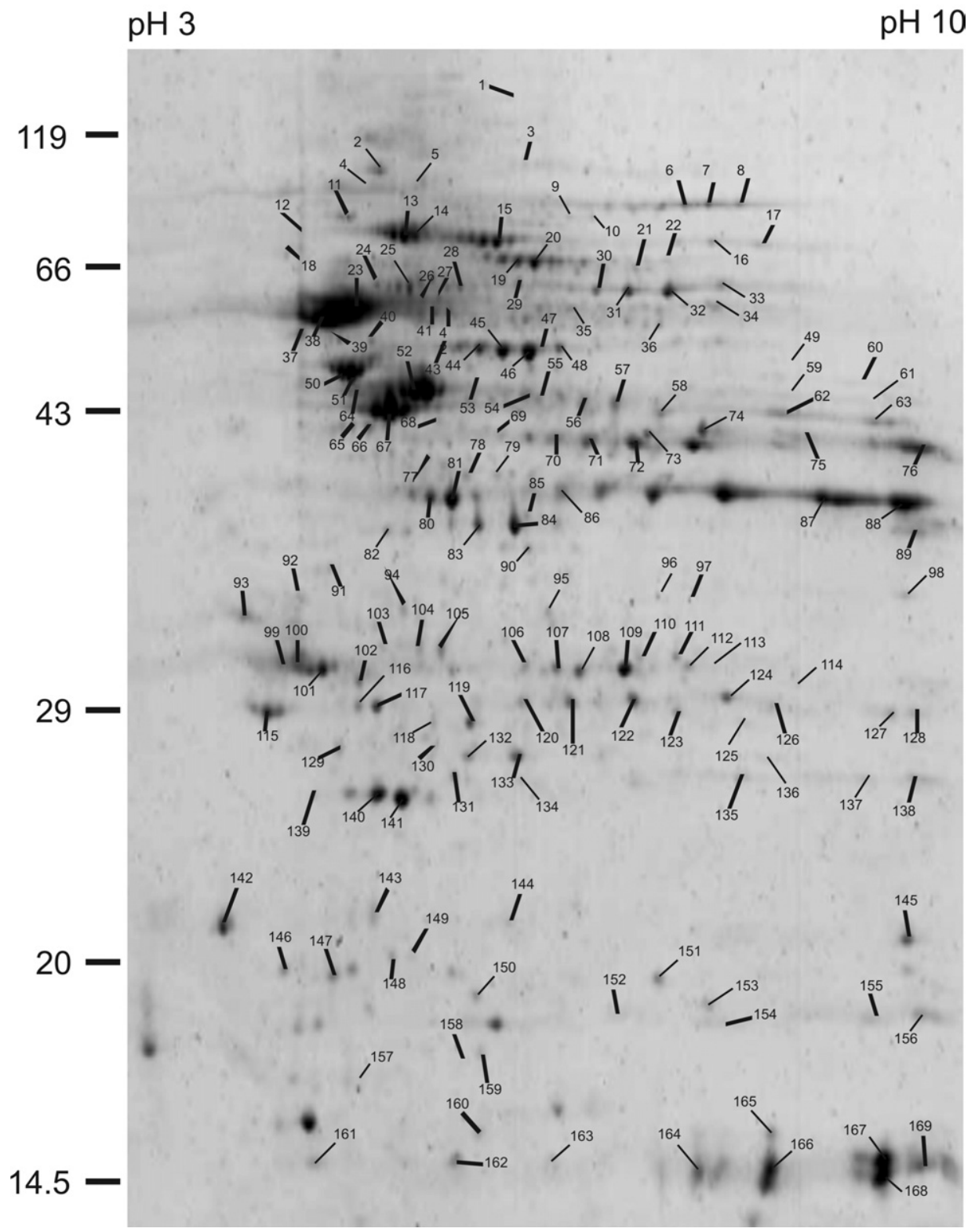

Fig. 2. Two-dimensional map of rat brain proteins. A representative example of a Coomassie-stained gel $(18 \mathrm{~cm} \times 18 \mathrm{~cm})$ loaded with $750 \mu \mathrm{g}$ proteins that were isolated from young adult rat cerebellum. The vast majority $(>90 \%)$ of the marked 169 spots were detected on gels run with either cerebellum or IC samples. See Tables 1 and 2 for quantitative differences between matching spots in different brain regions, as determined by densitometric analysis of RuBP-stained replicate gels. An unabbreviated list of all annotated proteins is provided as Supplemental Table 1.

than two gels for the other region; these were termed 'exclusive spots.' A total of $18(11 \%)$ exclusive spots were detected and subjected to a stringent manual revision. The revision revealed that several exclusive spots had intensities slightly above the detection limit, yet slightly below the detection limit in the reference sample. This situation turned low-intensity spots into artificial exclusive spots. After removing such artifacts, a total of six (4\%; Table 1) exclusive IC spots and two (1\%; Table 2) exclusive cerebellar spots remained. For example, the $\mathrm{Ca}^{2+}$-binding protein calbindin (spot 115) was detected exclusively in the cerebellum (Fig. 4). These data fit well with results of previous immunohistochemical studies (Celio, 1990; Friauf, 1994; Tardif et al., 2003) and are in accordance with our own analysis on the transcript level, which showed a high abundance of calbindin mRNA in the Purkinje cells of the cerebellum, yet no signal in the IC (Fig. 4h, i).

The second and largest group comprised 115 spots $(68 \%)$ that were detected and matched on at least two gels for both brain regions and termed 'major spots.' For these, we calculated AFs and we found a total of 32 major spots with significantly increased intensity. For example, aconitate hydratase, an enzyme of the citric acid-cycle, was detected in three isoform spots (spots 6-8) which were all 


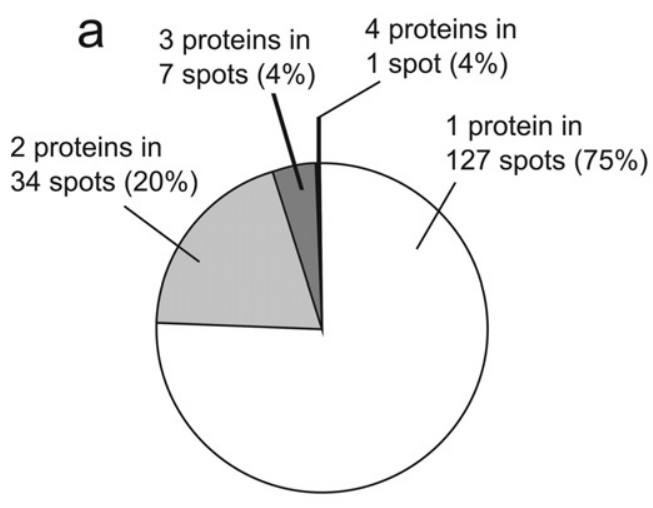

Number of proteins per spot

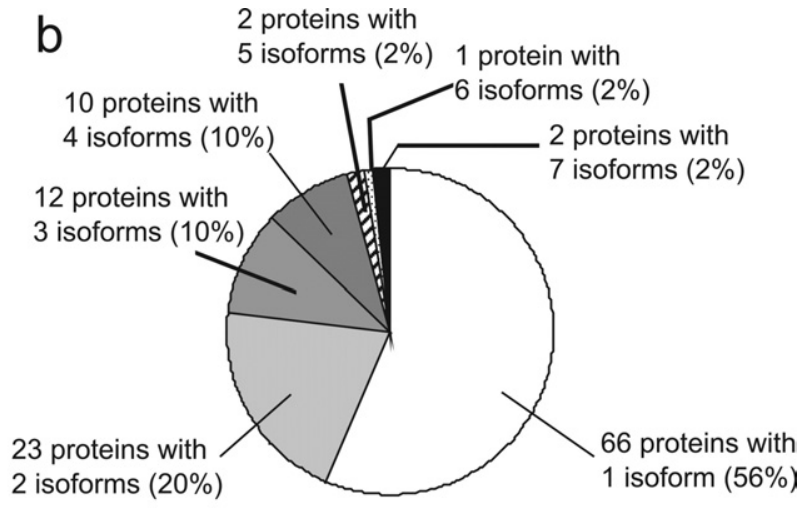

Isoform spots per protein

Fig. 3. Summary of annotated protein spots. (a) Number of different proteins detected per annotated spot on the two-dimensional gel in Fig. 1. In 75\% of all spots, only one protein was identified, in the remaining $25 \%$, two to four proteins were identified. (b) Number of isoform spots per protein. Fifty-six percent of all proteins were identified in only one spot, the remaining $44 \%$ were detected in up to seven isoform spots.

classified as major spots, each demonstrating significantly higher abundance of the protein in the IC (Fig. 5). Of 15 spots with increased intensity in the IC, one spot contained two and another three different proteins. In the cerebellum,
17 spots with increased intensity were found (three spots contained two and one spot three different proteins).

The third group contained 37 spots (22\%) which could not be detected or matched reliably on at least two gels for

Table 1. Proteins with higher abundance in the inferior colliculus

\begin{tabular}{|c|c|c|c|c|c|c|c|c|}
\hline Spot & Gene name & Protein name & Swiss-Prot & Mowse & \# & $\%$ & AF IC & $P$ \\
\hline 1 & Dnm1 & Dynamin-1 & P21575 & 65 & 19 & 21 & $\infty$ & ok \\
\hline 3 & Dnm1 & Dynamin-1 & P21575 & 144 & 30 & 27 & $\infty$ & ok \\
\hline 3 & Pygb & Glycogen phosphorylase, brain form & P53534 & 54 & 16 & 17 & $\infty$ & ok \\
\hline 10 & Nsf & Vesicle-fusing ATPase & P46460 & 116 & 22 & 29 & $\infty$ & ok \\
\hline 27 & Dpysl2 & Dihydropyrimidinase related protein-2 & P47942 & $184^{\mathrm{m}}$ & 34 & 40 & $\infty$ & ok \\
\hline 27 & Tuba2 & Tubulin alpha-2 chain & Q6P9V9 & $184^{\mathrm{m}}$ & 34 & 44 & $\infty$ & ok \\
\hline 100 & Ywhag & 14-3-3 Protein gamma & P61983 & 162 & 26 & 59 & $\infty$ & ok \\
\hline 145 & Cfl1 & Cofilin-1 & P45592 & 62 & 11 & 44 & $\infty$ & ok \\
\hline 5 & Hspcb & Heat shock protein HSP 90-beta & P34058 & 168 & 35 & 38 & 4.4 & ** \\
\hline 8 & Aco2 & Aconitate hydratase, mitochondrial & Q9ER34 & 128 & 23 & 28 & 3.1 & * \\
\hline 17 & Tkt & Transketolase & P50137 & 161 & 22 & 33 & 3.0 & * \\
\hline 111 & $\mathrm{Ca} 2$ & Carbonic anhydrase II & P27139 & 121 & 14 & 57 & 3.0 & ** \\
\hline 111 & Kcnip2 & Kv channel-interacting protein 2 & Q9JM59 & 53 & 9 & 26 & 3.0 & ** \\
\hline 117 & Uchl1 & Ubiquitin carboxyl-terminal hydrolase isozyme L1 & Q00981 & 89 & 11 & 57 & 2.6 & ** \\
\hline 156 & Ppia & Peptidyl-prolyl cis-trans isomerase A & P10111 & 95 & 11 & 52 & 2.5 & * \\
\hline 7 & Aco2 & Aconitate hydratase, mitochondrial & Q9ER34 & 175 & 28 & 36 & 2.2 & * \\
\hline 57 & Glu1 & Glutamine synthetase & P09606 & $237^{\mathrm{m}}$ & 17 & 33 & 2.1 & ** \\
\hline 57 & Idh1 & Isocitrate dehydrogenase [NADP] cytoplasmic & P41562 & $237^{m}$ & 29 & 54 & 2.1 & ** \\
\hline 57 & Sh3Bp5 & SH3 domain-binding protein 5 & Q91Y80 & 51 & 10 & 18 & 2.1 & ** \\
\hline 116 & Uchl1 & Ubiquitin carboxyl-terminal hydrolase isozyme L1 & Q00981 & 63 & 9 & 52 & 2.1 & ** \\
\hline 56 & Glu1 & Glutamine synthetase & P09606 & 146 & 25 & 48 & 1.9 & ** \\
\hline 6 & Aco2 & Aconitate hydratase, mitochondrial & Q9ER34 & 211 & 31 & 38 & 1.8 & $* *$ \\
\hline 48 & Eno1 & Alpha enolase & P04764 & 67 & 14 & 24 & 1.8 & * \\
\hline 78 & Ddah1 & NG,NG-dimethylarginine dimethylaminohydrolase 1 & O08557 & 93 & 12 & 27 & 1.6 & ** \\
\hline 16 & Tkt & Transketolase & P50137 & 160 & 22 & 39 & 1.5 & * \\
\hline 130 & Park7 & DJ-1 protein & O88767 & 58 & 10 & 46 & 1.2 & $*$ \\
\hline
\end{tabular}

Lists all protein spots $(n=21)$ with significantly higher intensity in the IC. Abbreviations: Spot, position of the spot on the gel in Fig. 1; Gene name, Protein name, taken from the corresponding Swiss-Prot entry; Swiss-Prot, Swiss-Prot primary accession number; Mowse, probability-based Mowse score achieved by the data set when submitted to a Mascot peptide mass fingerprint search; scores $>50$ indicate a significant $(P<0.05)$ hit in the Rattus database; $\mathrm{m}$, indicates a mixture of two proteins detected in the initial search; second pass searches were routinely performed; \#, number of matched peptides; \%, sequence coverage attained by the matching peptides; AF IC, abundance factor for the IC, calculated by dividing the mean spot intensity in the IC by the mean spot intensity in the cerebellum; spots marked " $\infty$ " were below the detection limit in the cerebellum, resulting in an infinite abundance factor (exclusive spots); $P$, significance of abundance factors; ok, exclusive spot passed manual revision.

${ }^{*} P \leq 0.05$, significant.

${ }^{* *} P \leq 0.01$, highly significant. 
Table 2. Proteins with higher abundance in the cerebellum

\begin{tabular}{|c|c|c|c|c|c|c|c|c|}
\hline Spot & Gene name & Protein name & Swiss-Prot & Mowse & $\#$ & $\%$ & AF Cer & $P$ \\
\hline 55 & Ckb & Creatine kinase, $B$ chain & P07335 & $103^{m}$ & 22 & 23 & $\infty$ & ok \\
\hline 55 & Glu1 & Glutamine synthetase & P09606 & $103^{m}$ & 22 & 25 & $\infty$ & ok \\
\hline 115 & Calb1 & Calbindin & P07171 & 80 & 11 & 49 & $\infty$ & ok \\
\hline 143 & Mbp & Myelin basic protein $\mathrm{S}$ & P02688 & 79 & 13 & 61 & 6.60 & $\star *$ \\
\hline 101 & Calb2 & Calretinin & P47728 & $161^{\mathrm{m}}$ & 15 & 57 & 4.79 & $* *$ \\
\hline 101 & Ywhaz & 14-3-3 protein zeta/delta & P63103 & $161^{\mathrm{m}}$ & 20 & 56 & 4.79 & $* *$ \\
\hline 93 & Ywhae & 14-3-3 protein epsilon & P62260 & 155 & 20 & 75 & 3.37 & * \\
\hline 26 & Dpysl2 & Dihydropyrimidinase related protein-2 & P47942 & 59 & 16 & 18 & 3.24 & $* *$ \\
\hline 52 & $\mathrm{Ckb}$ & Creatine kinase, $B$ chain & P07335 & 235 & 25 & 70 & 2.61 & ** \\
\hline 15 & Alb & Serum albumin & $\mathrm{P} 02770$ & 91 & 18 & 32 & 2.21 & ** \\
\hline 77 & $\operatorname{ldh} 3 a$ & $\begin{array}{l}\text { Isocitrate dehydrogenase [NAD] subunit } \\
\text { alpha, mitochondrial }\end{array}$ & Q99NA5 & 112 & 20 & 38 & 1.97 & * \\
\hline 99 & Ywhag & 14-3-3 Protein gamma & P61983 & $315^{\mathrm{m}}$ & 51 & 55 & 1.97 & * \\
\hline 99 & Ywhaq & 14-3-3 Protein theta & P68255 & $315^{\mathrm{m}}$ & 51 & 64 & 1.97 & * \\
\hline 99 & Ywhaz & 14-3-3 Protein zeta/delta & P63103 & $315^{\mathrm{m}}$ & 51 & 62 & 1.97 & * \\
\hline 18 & Nefl & $68 \mathrm{kDa}$ neurofilament protein & P19527 & 66 & 18 & 17 & 1.93 & * \\
\hline 146 & Snca & Alpha-synuclein & P37377 & 81 & 10 & 60 & 1.85 & * \\
\hline 53 & Ckb & Creatine kinase, $B$ chain & P07335 & 50 & 13 & 20 & 1.84 & * \\
\hline 11 & Hspa5 & $78 \mathrm{kDa}$ glucose-regulated protein & P06761 & 164 & 27 & 42 & 1.80 & * \\
\hline 11 & Hspa8 & Heat shock cognate $71 \mathrm{kDa}$ protein & P63018 & 54 & 12 & 22 & 1.80 & * \\
\hline 132 & Park7 & DJ-1 protein & O88767 & 54 & 8 & 40 & 1.50 & ** \\
\hline 50 & Eno2 & Gamma enolase & P07323 & 237 & 26 & 73 & 1.47 & * \\
\hline 83 & Mdh1 & Malate dehydrogenase, cytoplasmic (m) & P14152 & 73 & 13 & 44 & 1.41 & * \\
\hline 30 & Pkm2 & Pyruvate kinase, isozymes M1/M2 & P11980 & 98 & 17 & 31 & 1.38 & * \\
\hline 104 & $\operatorname{Rps} 4 \mathrm{x}$ & $40 \mathrm{~S}$ ribosomal protein $\mathrm{S} 4, \mathrm{X}$ isoform & P62703 & 64 & 12 & 44 & 1.35 & * \\
\hline 104 & Ywhag & 14-3-3 Protein gamma & P61983 & 51 & 14 & 35 & 1.35 & * \\
\hline
\end{tabular}

Lists all protein spots $(n=19)$ with significantly higher intensity in the cerebellum. Abbreviations: Spot, position of the spot on the gel in Fig. 1; Gene name, Protein name, taken from the corresponding Swiss-Prot entry; Swiss-Prot, Swiss-Prot primary accession number; Mowse, probability-based Mowse score achieved by the data set when submitted to a Mascot peptide mass fingerprint search; scores $>50$ indicate a significant $(P<0.05)$ hit in the Rattus database; ${ }^{m}$, indicates a mixture of up to three proteins detected in the initial search; second pass searches were routinely performed; \#, number of matched peptides; \%, sequence coverage attained by the matching peptides; AF Cer, abundance factor for the cerebellum, calculated by dividing the mean spot intensity in the cerebellum by the mean spot intensity in the inferior colliculus; spots marked " $\infty$ " were below the detection limit in the IC, resulting in an infinite abundance factor (exclusive spots); $P$, Significance of abundance factors; ok, exclusive spot passed manual revision.

${ }^{*} P \leq 0.05$, significant.

** $P \leq 0.01$, highly significant.

either brain region. These were consequently termed 'nonspots' and excluded from further quantitative analysis.

Twenty gene products were more prominent in the IC. Among them, at least three (dynamin-1, cofilin-1, vesiclefusing ATPase) are involved in vesicular trafficking and exo-/endocytosis (Hinshaw, 2000; Whiteheart et al., 2001; Pavlov et al., 2007). On the other hand, 22 gene products were more prominent in the cerebellum. Among those, we identified two calcium-binding proteins (calbindin, calretinin) and four different 14-3-3 proteins.

Taken together, out of 169 spots analyzed, a different abundance in either IC or cerebellum could be detected in 40 spots $(24 \%)$. Of those, 21 spots (with 26 proteins, representing 20 genes) were more prominent in the IC, and 19 spots in the cerebellum (with 25 proteins representing 22 genes).

\section{Validation experiments: Western blots}

We finally performed a series of antibody binding experiments to validate the accuracy of our proteomic data. To do so, five proteins were selected, namely calbindin, calretinin, 14-3-3 protein gamma, cofilin-1, and dynamin-1.
The proteomics results had revealed a higher abundance in the cerebellum for the first two (Table 1), whereas the latter three were more abundant in the IC (Table 2). We analyzed their presence in the cytosolic fraction of both the cerebellum and the IC. In the cerebellum, the Western blots demonstrated a virtually exclusive expression of calbindin and a higher signal for calretinin (Fig. 6). In contrast, 14-3-3 protein gamma, cofilin-1, and dynamin-1 were more prominent in the IC (Fig. 7). Together, these findings were in line with the results obtained by our semi-quantitative proteomic analysis, thereby confirming its validity.

\section{DISCUSSION}

We have performed a differential proteomic analysis of the rat cerebellum and IC under non-pathological conditions. The two brain regions are anatomically and functionally distinct from each other, but both play a role in sensorimotor integration. Despite this relation, our results demonstrate pronounced differences between their proteomes. In the IC, we found an increase of proteins involved in vesicular trafficking. In the cerebellum, we detected an increase 

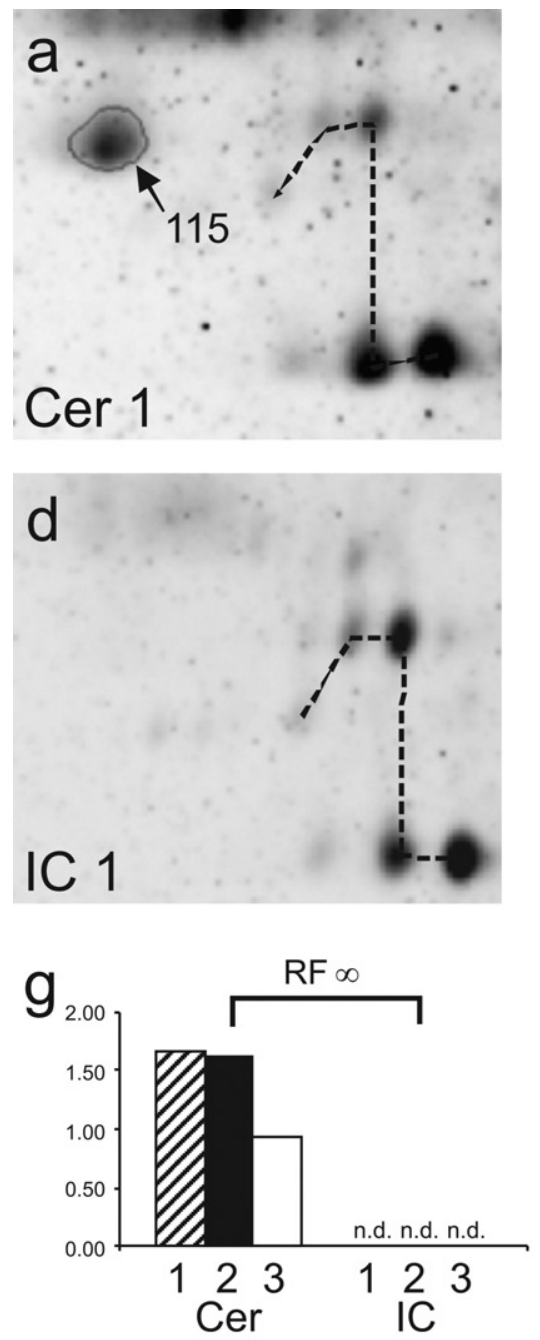
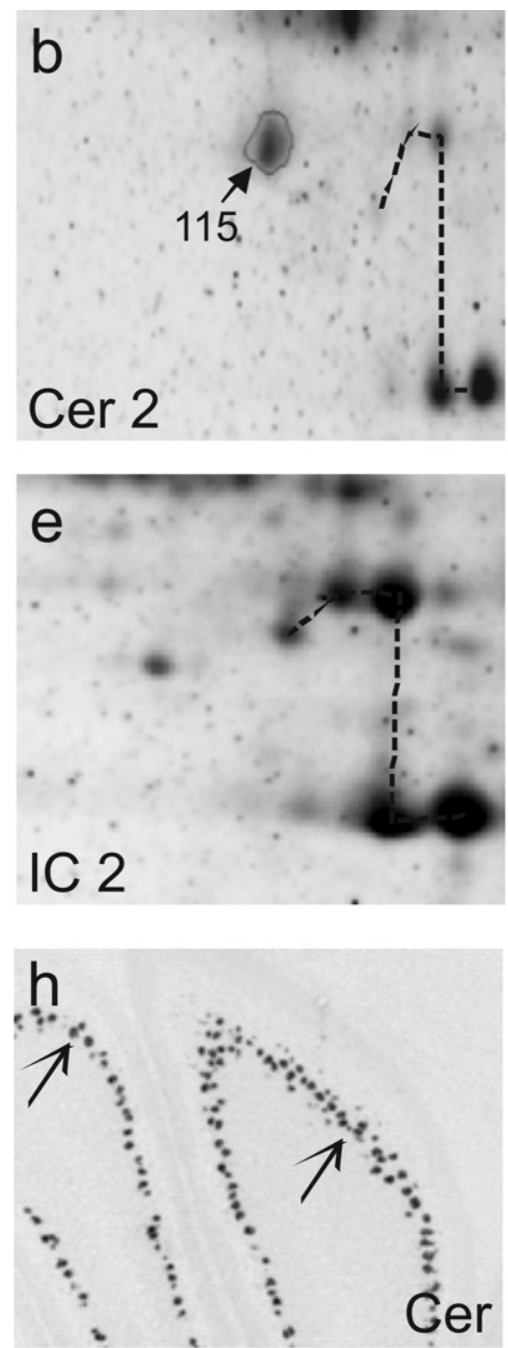
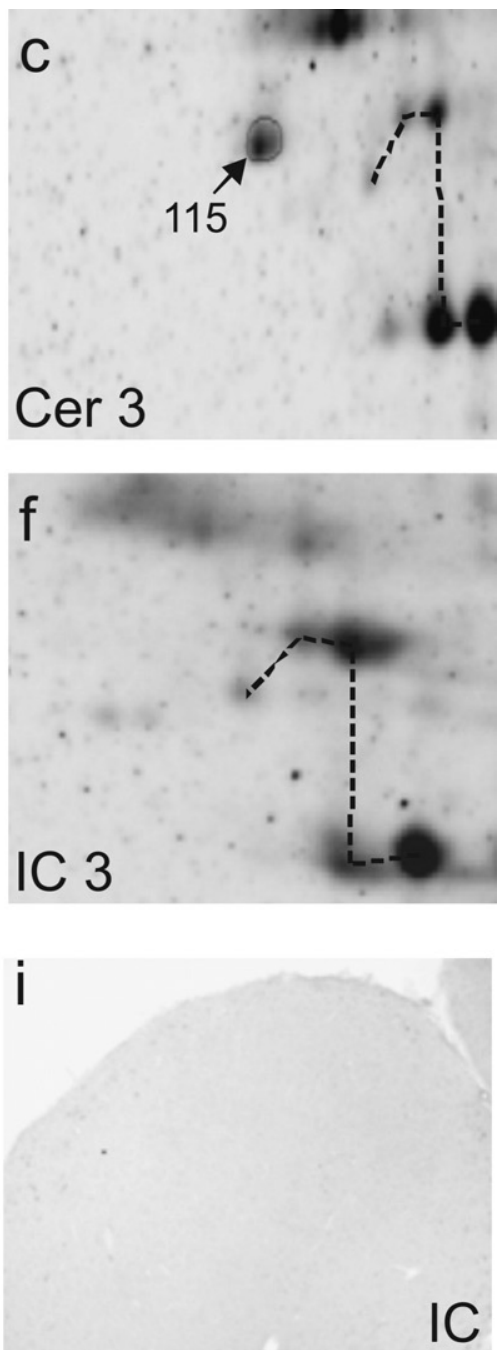

Fig. 4. Calbindin was exclusively detected in the cerebellum. On all three RuBP-stained analytical gels loaded with cerebellum samples (Cer 1-Cer 3 ), the $\mathrm{Ca}^{2+}$-binding protein calbindin (spot 115) was prominently represented $(\mathrm{a}-\mathrm{c})$. The corresponding spot was below the detection limit on all three gels (IC 1-IC 3) loaded with IC samples (d-f). The z-shaped spot pattern facilitated gel matching (dashed line in a-f). Spot detection, volume determination and normalization were performed using Proteomweaver, resulting in an infinite AF for calbindin ( $g$ ). mRNA in situ hybridization with calb1 specific antisense probes supports these findings on the transcript level ( $\mathrm{h}$, i). calb1 Was strongly expressed in Purkinje cells of the cerebellum (arrows in $\mathrm{h}$ ), but below the detection limit in the IC of young adult rats (i). Dorsal is up and caudal to the right in $\mathrm{h}$ and $\mathrm{i}$.

of proteins involved in intracellular signaling cascades. Additionally, several proteins indicate regional differences in energy metabolism. The accuracy of our semi-quantitative proteomics analysis was demonstrated by Western blotting experiments performed on a selected number of proteins. Moreover, the experiments provided further evidence that this proteomics approach provides quantitative assessments, enabling comparisons between protein abundances rather than simply distinguishing between 'yes' and 'no.'

\section{Higher abundance of trafficking proteins in the IC}

Three of 20 gene products with increased intensity in the IC are reportedly involved in vesicular trafficking and exo-/ endocytosis. Dynamin-1, a large GTPase, plays a central role in synaptic vesicle recycling and endocytosis in general, pinching clathrin-coated vesicles of the membrane
(Hinshaw, 2000). Dynamin-1 is the neuron-specific of three mammalian isoforms, and a known substrate of protein kinase C (Liu et al., 1994). In addition, numerous splice variants of dynamin exist (Cao et al., 1998), and it is likely that the exclusive spots for dynamin-1 that we detected (spots 1 and 3; Table 1) represent IC-specific forms of dynamin-1. Cofilin-1 is the non-muscle isoform of an actindepolymerizing factor which enhances the dynamics of filament assembly and has critical functions in endocytosis and cytokinesis (Pavlov et al., 2007; Zhu et al., 2007). The importance of cofilin-1 in the nervous system is underlined by the fact that knockout mice die in utero due to severe defects in neurogenesis (Gurniak et al., 2005). The vesicle-fusing ATPase (NSF) was one of the first components of the vesicular trafficking machinery described (Whiteheart et al., 2001). In addition to a major role in neurotransmitter release at the synapse, NSF also plays a role in 

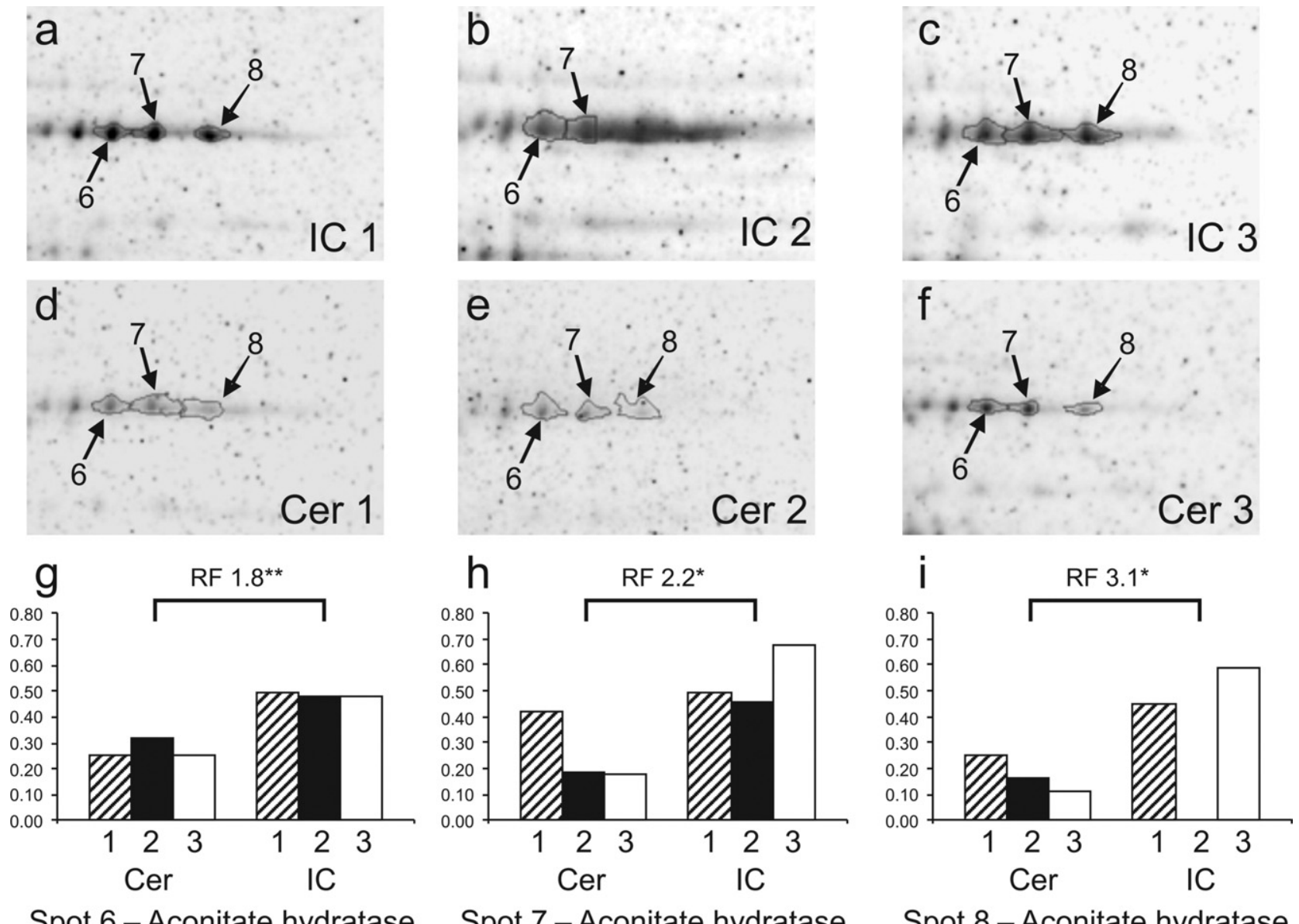

\section{Spot 6 - Aconitate hydratase}

Spot 7 -Aconitate hydratase

Spot 8 - Aconitate hydratase

Fig. 5. Aconitate hydratase, an enzyme of the carboxylic acid cycle, was more abundant in the IC. It was detected in spots $6-8$ on both IC (a-c) and cerebellum ( $d-f$ ) analytical gels. Spot detection, volume determination and normalization were performed using Proteomweaver and revealed a significantly higher amount of aconitate hydratase in the IC in all three spots $(\mathrm{g}-\mathrm{i})$. ${ }^{*}$ Significantly higher abundance $(P \leq 0.05),{ }^{* *}$ highly significantly higher abundance $(P \leq 0.01)$.

intracellular transport from the endoplasmic reticulum to the Golgi stack (Muller et al., 1999). NSF and cofilin activity is regulated by phosphorylation (Nakano et al., 2003; Huynh et al., 2004). Thus, the exclusive spots could indicate specific phosphorylation states present in the IC (spots 10 and 145; Table 1). Taken together, the changes detected in dynamin-1, cofilin-1 and NSF expression point toward an increased importance and/or altered regulation of vesicular trafficking processes in the IC. The constant and precisely timed neuronal activity found in auditory centers is a likely explanation for this observation, as it necessitates a constant and reliable function of vesicular trafficking and neurotransmitter release, probably more so than in non-auditory regions, such as the cerebellum.

\section{Higher abundance of $\mathrm{Ca}^{2+}$-binding and 14-3-3 proteins in the cerebellum}

Among the 22 gene products with higher abundance in the cerebellum were the two $\mathrm{Ca}^{2+}$-binding proteins calbindin and calretinin (=calbindin 2 ). These closely related cytosolic proteins bind free $\mathrm{Ca}^{2+}$-ions and thus contribute to the fast $\mathrm{Ca}^{2+}$-buffer capacity of cells. Strong expression of calbindin in cerebellar Purkinje cells was demonstrated by immunohistochemistry (Celio, 1990; Fortin et al., 1998; Bastianelli, 2003), whereas granule cells express calretinin (Resibois and Rogers, 1992; Marini et al., 1997; Bearzatto et al., 2005). In contrast, only a faint expression of calbindin was shown in the IC (Celio, 1990; Friauf, 1994; Tardif et al., 2003). Calretinin expression is present in the IC, but restricted mainly to the dorsal cortex and the commissure, and down-regulated with age (Lohmann and Friauf, 1996; Zettel et al., 1997). Thus, our proteomic data match with protein expression data obtained with classical methods. The importance of $\mathrm{Ca}^{2+}$-buffering for proper motor control is well documented, and its perturbation can result in ataxia and kinetic tremor (Airaksinen et al., 1997). Interestingly, a recent proteomic study of $129 / \mathrm{Sv}$ mice, a strain that displays impaired motor skill, has demonstrated a down-regulation of calbindin in the cerebellum (Pollak et al., 2005). In calretinin-deficient mice, targeted expression of calretinin in cerebellar granule cells restores normal motor control (Bearzatto et al., 2005). Another group of proteins showing higher abundance in the cerebellum was 14-3-3 proteins; four different isoforms of these abundant 


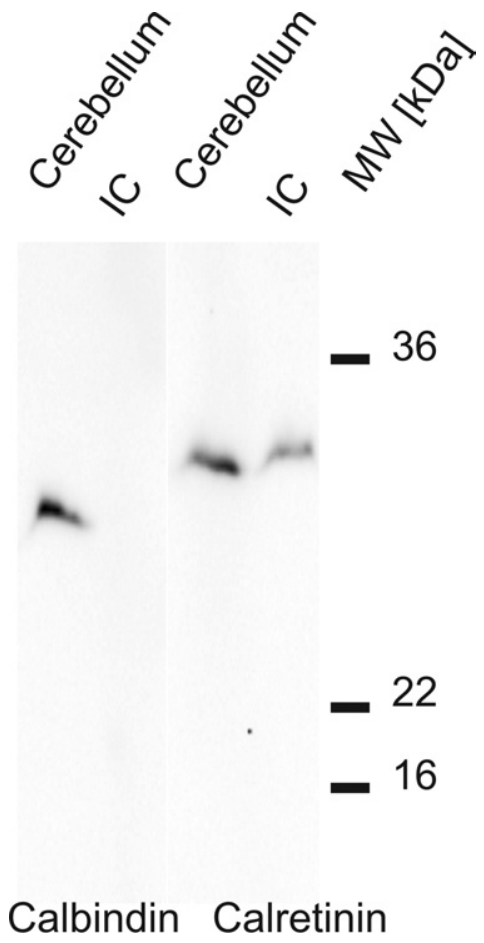

Fig. 6. Western blot analysis from the cytosolic fractions of cerebellum and IC tissue, demonstrating calbindin and calretinin immunoreactivity. Calbindin was virtually absent in the IC, consistent with the AF of $\infty$ shown by proteomics. Calretinin immunoreactivity was present in both brain regions, but the signal was stronger in the cerebellum. This result is in line with a more than fourfold higher abundance demonstrated by proteomics.

brain proteins were found in spots 93, 99, 101 and 104. With more than 200 binding partners known, 14-3-3 proteins are linked to numerous cellular processes, ranging from cell cycle control and apoptosis to neurotransmitter synthesis (van Heusden, 2005). Changes in 14-3-3 expression have been demonstrated in conjunction with numerous neuronal diseases, including Alzheimer's disease, Down syndrome, Parkinson disease and diffuse Lewy body disease (Fountoulakis et al., 1999; Kawamoto et al., 2002; Xu et al., 2002a). The functional implications of changes in 14-3-3 levels are not always clear. For example, 14-3-3 epsilon and zeta isoforms have been shown to mediate ataxin-1 neurotoxicity in spinocerebellar ataxia (Chen et al., 2003a). This indicates the importance of 14-3-3 proteins for proper motor control, and may explain the increased protein levels we detected in the cerebellum. In contrast, 14-3-3 gamma protein is strongly increased in cerebrospinal fluids of patients with Creutzfeldt-Jacob disease, but 14-3-3 gamma deficient mouse strains show no altered pathogenesis of prion diseases or any other obvious phenotype (Kretzschmar et al., 1996; Wiltfang et al., 1999; Steinacker et al., 2005).

\section{Regional differences in energy metabolism}

We detected abundance differences of several metabolic enzymes which indicate a difference in the way energy is mobilized in the two brain regions analyzed. Seven out of
10 enzymes involved in glycolysis were detected in our study, distributed in a total of 34 spots. Two of these, (gamma enolase, spot 50 and pyruvate kinase, spot 30 , Table 2) were significantly more abundant in the cerebellum, hinting at increased activity of this pathway in the cerebellum. In contrast, we found a higher abundance of transketolase (spots 16 and 17, Table 1), a key enzyme of the phosphogluconate pathway, in the IC. Transketolase rejoins the phosphogluconate pathway with glycolysis by generating glyceraldehyde-3-phosphate and fructose-6phosphate. Unlike glycolysis, the phosphogluconate pathway generates $\mathrm{NADPH} / \mathrm{H}^{+}$, which is utilized in the synthesis of steroids and lipids instead of being utilized in oxidative phosphorylation. The role of the phosphogluconate pathway in the IC remains unclear, but it has been shown that transketolase activity in the brain is tightly regulated, and deficiencies in transketolase activity are seen in patients with Alzheimer's disease and Wernicke-Korsakoff syndrome (Martin et al., 1995; Paoletti et al., 1997; Xu et al., 2002b). Three enzymes of the citric acid cycle were also found to be differently expressed: isocitrate dehydrogenase and malate dehydrogenase were more prominent in the cerebellum and aconitate hydratase was more prominent in the IC. This may indicate differential regulation of this important metabolic pathway in the brain regions analyzed, although neither enzyme represents a classical site of citric acid cycle regulation. Two other differently expressed proteins display the different forms of energy mobilization in IC and cerebellum. On the one hand, we found an increase of glycogen phosphorylase in the IC, an enzyme that mobilizes glucose from glycogen, a process that mainly ensures mid- to long-term preservation of energy pools and could represent an adaptation to maintain the constant and precisely timed activity required in audi-

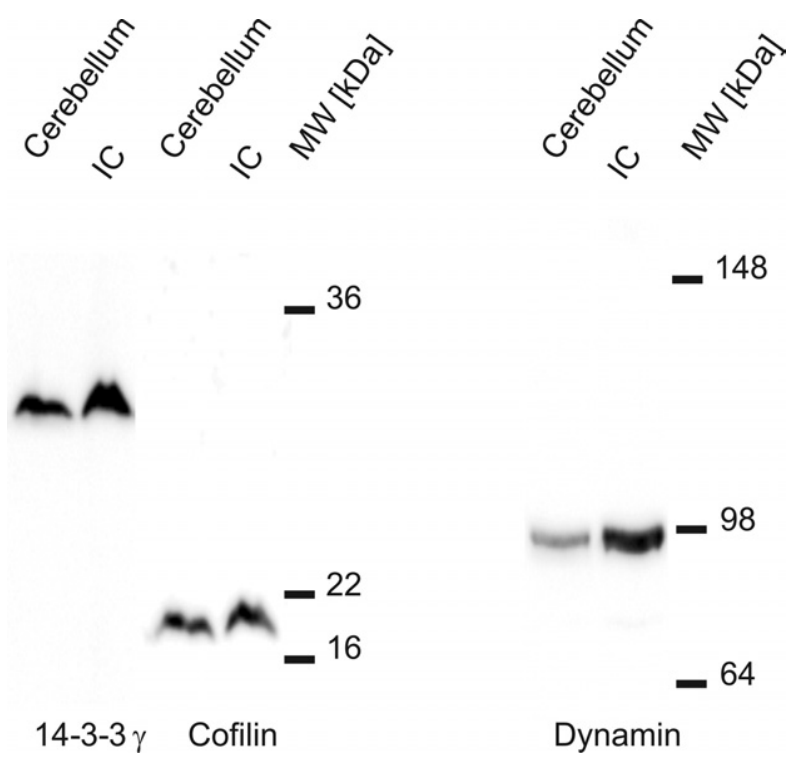

Fig. 7. Western blot analysis from the cytosolic fractions of cerebellum and IC tissue, demonstrating immunoreactivity for 14-3-3 protein gamma, cofilin-1, and dynamin-1. For each protein, a stronger band was present in the IC. The results are in accordance with the proteomics data which had also shown a higher abundance in the IC. 
tory neurons. On the other hand, creatine kinase is more abundant in the cerebellum. This protein allows the immediate regeneration of ATP from energy-rich phosphocreatine. It has recently been demonstrated that diffusion is not sufficient to maintain ATP levels in cochlear hair bundles (Shin et al., 2007). These cellular processes are too far removed from mitochondria and rely on creatine kinase to constantly provide ATP. In the cerebellum, the large dendritic arbors of Purkinje cells may represent a similar situation, and explain the higher abundance of creatine kinase.

\section{A general map of common brain proteins}

Fountoulakis (2004) summarized data from 100 independent proteomic analyses of human brain tissue and listed 20 proteins, which occurred with a frequency of $57 \%$ and higher, all of them being housekeeping proteins. Nineteen of these common brain proteins were also detected in our study, further demonstrating their ubiquitous expression. As a result, there is a general similarity of the spot patterns obtained with IC and cerebellum samples ( 90\%). We conclude that annotations can be easily transferred to gels prepared with samples from different brain regions. Indeed, we have successfully transferred the annotations of the protein maps presented here to gels prepared with tissue from superior olivary complex, brainstem, and whole brain, as confirmed by multiple MALDI-MS measurements of matched spots (data not shown). This transfer is useful when analyzing brain regions of very small volume, such as the cochlear nuclear complex or the superior olivary complex, where tissue samples sufficient for preparative gels are hard to obtain. Differently intensive spots, detected on analytical gels, can be identified by running preparative gels using larger brain regions or even whole brain tissue, and transferring the annotations obtained there.

\section{Overlapping protein spots}

An overlap of different proteins in a single spot represents a problem for two-dimensional gel electrophoresis-based quantification methods (Pietrogrande et al., 2003; Campostrini et al., 2005). The number of spots for which we identified two or more overlapping proteins (25\%) fits with a published model which predicts the number of overlapping proteins (Pietrogrande et al., 2003; Campostrini et al., 2005). We are therefore confident that we indeed detected the majority of overlapping proteins. Out of 40 spots on IC or cerebellum gels displaying different intensity, only eight $(20 \%)$ contained overlapping proteins, for which quantification is of limited use. However, if overlapping proteins fit into the same functional group, such as two heat shock proteins in spot 11 or three different 14-3-3 proteins in spot 99 , a higher intensity of that group in general is likely. Moreover, the higher intensity of an overlapping protein in additional spots supports an increased abundance of that protein in general (e.g. creatine kinase, spots 52,53 and 55). A considerably higher Mowse score often indicates one protein as the major component of a spot, which implies that an increase in spot intensity is mainly due to the higher abundance of this protein (e.g. carbonic anhydrase II and Kv channel-interacting protein 2 in spot 111). Based on these considerations, limited information on differently expressed proteins can be gained even from spots with overlapping proteins, although validation with independent methods (such as immunohistochemistry or MSbased quantification) is essential.

\section{Limitations and drawbacks of the technique}

Aside from the caveat mentioned above (overlap of different proteins in a single spot), there are other limitations that one should not conceal. Global proteomic studies are screening studies and can provide candidate molecules, but they cannot replace anatomical or physiological experiments. It is mandatory that the results of a proteomic study be validated and followed up by independent experiments. Western blotting and immunohistochemistry represent obvious choices to validate expression levels (supplemented by RNA-based techniques when antibodies are not available). Intensive data mining can help to trim down a list of candidates to a more manageable size for low-throughput follow-up studies. Following this, results from pharmacological, RNAi, or knockout experiments can provide a link from candidate to function. When this rule is followed, the drawbacks of the method are considerably reduced.

Limited coverage is another caveat to be considered. Our study and many others demonstrate that today's proteomics technology is only applicable to abundant and easily soluble proteins. Reduction of the sample complexity by pre-fractionation represents a possible solution to this problem. Several pre-fractionation protocols have been developed that are applicable to brain tissue, including those suitable for plasma membrane proteins, which may be most interesting to neuroscientists (Li et al., 2004; Guillemin et al., 2005; Schindler et al., 2006, 2008). Separating the proteome into less complex sub-fractions is generally limited by the amount of starting tissue available, as each separating step involves loss of proteins. Especially when analyzing small brain regions, highly sensitive proteomic methods are required, such as in-gel difference electrophoresis (Tonge et al., 2001) or gel-free approaches based on multidimensional chromatographic separation of complex protein mixtures (Gevaert et al., 2007).

Finally, our proteomics approach, like many global gene expression studies (e.g. microarray analysis), cannot attribute observed differences in protein level to neurons or glial cells. A distinction between these two cell types can only be done by obtaining pure samples, which is endeavored in the brain, or by performing follow-up experiments, for example immunocytochemistry on identified cells.

\section{CONCLUSION}

Our results show pronounced differences in the proteome between the IC and the cerebellum, despite their shared role in sensorimotor integration. They also demonstrate that regional differences in the protein pattern can be resolved using gel-based proteomic methods. In addition, 
the protein map presented here represents a resource that facilitates the annotation of proteins in follow-up studies.

The present study represents a proof-of-principle demonstration of the feasibility of a differential analysis of relatively small brain regions, such as the $\mathrm{IC}$ and other auditory relay stations. It thus provides the groundwork for elaborate proteomic studies. In the auditory system, such studies may comprise an analysis of developmental changes in a given auditory region and a multiplexed analysis of several auditory brainstem areas. They may be complemented by the search for alterations induced by genetic mutations, e.g. those causing deafness. As the alterations may be restricted to specific regions or be diametrically opposed in different regions, they may elude detection when heterogeneous organs, such as the brain, are analyzed as a whole. The application of fluorescent dyes in two-dimensional differential gel electrophoresis (2D-DIGE; Unlu et al., 1997; Tonge et al., 2001; Van den Bergh and Arckens, 2004) enables the detection of quantitative differences between samples in a single gel and has unveiled the potential of gel-based proteomics (Van den Bergh et al., 2006). In conclusion, the generation of quantitative proteome databases will yield a comprehensive understanding of the characteristic protein profile, and thus the molecular phenotype, of a given brain region. All in all, they will thus provide a basis for future physiological studies.

Acknowledgments-This work was funded in part by the DFG Graduiertenkolleg 845, the Stiftung für Innovation (961-386261/ 827), and the Nano+Bio Center Kaiserslautern. We are indebted to the group of Dr. Gereon Niedner-Schatteburg for providing access to the MALDI mass spectrometer. We would also like to thank Anja Feistner, Tina Kehrwald, and Kornelia Ociepka for expert technical help and Dr. Christine B. Gurniak for the $n$-cofilin antibody.

\section{REFERENCES}

Airaksinen M, Eilers J, Garaschuk O, Thoenen H, Konnerth A, Meyer M (1997) Ataxia and altered dendritic calcium signaling in mice carrying a targeted null mutation of the calbindin D28k gene. Proc Natl Acad Sci U S A 94:1488-1493.

Bastianelli E (2003) Distribution of calcium-binding proteins in the cerebellum. Cerebellum 2:242-262.

Bearzatto B, Servais L, Roussel C, Gall D, Baba-Aissa F, Schurmans $S$, d'Exaerde AD, Cheron G, Schiffmann SN (2005) Targeted calretinin expression in granule cells of calretinin-null mice restores normal cerebellar functions. FASEB J 19:380-382.

Becker M, Schindler J, Nothwang HG (2006) Neuroproteomics: the tasks lying ahead. Electrophoresis 27:2819-2829.

Berggren K, Chernokalskaya E, Steinberg TH, Kemper C, Lopez MF, Diwu Z, Haugland RP, Patton WF (2000) Background-free, high sensitivity staining of proteins in one- and two-dimensional sodium dodecyl sulfate-polyacrylamide gels using a luminescent ruthenium complex. Electrophoresis 21:2509-2521.

Blaesse P, Guillemin I, Schindler J, Schweizer M, Delpire E, Khiroug L, Friauf E, Nothwang HG (2006) Oligomerization of KCC2 correlates with development of inhibitory neurotransmission. J Neurosci 26:10407-10419.

Campostrini N, Areces LB, Rappsilber J, Pietrogrande MC, Dondi F, Pastorino F, Ponzoni M, Righetti PG (2005) Spot overlapping in two-dimensional maps: A serious problem ignored for much too long. Proteomics 5:2385-2395.
Cao H, Garcia F, McNiven MA (1998) Differential distribution of dynamin isoforms in mammalian cells. Mol Biol Cell 9:2595-2609.

Casseday JH, Covey E (1996) A neuroethological theory of the operation of the inferior colliculus. Brain Behav Evol 47:311-336.

Celio MR (1990) Calbindin-D-28K and parvalbumin in the rat nervous system. Neuroscience 35:375-475.

Chen HK, Fernandez-Funez P, Acevedo SF, Lam YC, Kaytor MD, Fernandez MH, Aitken A, Skoulakis EMC, Orr HT, Botas J, Zoghbi HY (2003a) Interaction of Akt-phosphorylated ataxin-1 with 14-3-3 mediates neurodegeneration in spinocerebellar ataxia type 1. Cell 113:457-468.

Chen W, Ji JG, Xu XM, He SZ, Ru BG (2003b) Proteomic comparison between human young and old brains by two-dimensional gel electrophoresis and identification of proteins. Int $\mathrm{J}$ Dev Neurosci 21:209-216.

Cheon MS, Fountoulakis M, Dierssen M, Ferreres JC, Lubec G (2001) Expression profiles of proteins in fetal brain with Down syndrome. J Neural Transm Suppl 61:311-319.

Davis KA, Ramachandran R, May BJ (2003) Auditory processing of spectral cues for sound localization in the inferior colliculus. J Assoc Res Otolaryngol 4:148-163.

Denslow N, Michel ME, Temple MD, Hsu CY, Saatman K, Hayes RL (2003) Application of proteomics technology to the field of neurotrauma. J Neurotrauma 20:401-407.

Fortin M, Marchand R, Parent A (1998) Calcium-binding proteins in primate cerebellum. Neurosci Res 30:155-168.

Fountoulakis M (2004) Application of proteomics technologies in the investigation of the brain. Mass Spectrom Rev 23:231-258.

Fountoulakis M, Cairns N, Lubec G (1999) Increased levels of 14-3-3 gamma and epsilon proteins in brain of patients with Alzheimer's disease and Down syndrome. J Neural Transm Suppl 57:323-335.

Friauf E (1994) Distribution of calcium-binding protein calbindin-D-28K in the auditory system of adult and developing rats. J Comp Neurol 349:193-211.

Gevaert K, Van Damme P, Ghesquière B, Impens F, Martens L, Hensens K, Vandekerckhove J (2007) A la carte proteomics with an emphasis on gel-free techniques. Proteomics 7:2698-2718.

Gilman S (2000) The spinocerebellar ataxias. Clin Neuropharmacol 23:296-303

Guillemin I, Becker M, Ociepka K, Friauf E, Nothwang HG (2005) A subcellular prefractionation protocol for minute amounts of mammalian cell cultures and tissue. Proteomics 5:35-45.

Gurniak CB, Perlas E, Witke W (2005) The actin depolymerizing factor $n$-cofilin is essential for neural tube morphogenesis and neural crest cell migration. Dev Biol 278:231-241.

Hinshaw JE (2000) Dynamin and its role in membrane fission. Annu Rev Cell Dev Biol 16:483-519.

Huynh H, Bottini N, Williams S, Cherepanov V, Musumeci L, Saito K, Bruckner S, Vachon E, Wang XD, Kruger J, Chow CW, Pellecchia M, Monosov E, Greer PA, Trimble W, Downey GP, Mustelin T (2004) Control of vesicle fusion by a tyrosine phosphatase. Nat Cell Biol 6:831-839.

Ito $M$ (2005) Bases and implications of learning in the cerebellum: adaptive control and internal model mechanism. Prog Brain Res 148:95-109.

Kawamoto Y, Akiguchi I, Nakamura S, Honjyo Y, Shibasaki H, Budka $\mathrm{H}$ (2002) 14-3-3 Proteins in Lewy bodies in Parkinson disease and diffuse Lewy body disease brains. J Neuropathol Exp Neurol 61:245-253.

Kim SI, Voshol H, van Oostrum J, Hastings TG, Cascio M, Glucksman MJ (2004) Neuroproteomics: Expression profiling of the brain's proteomes in health and disease. Neurochem Res 29:1317-1331.

Kretzschmar HA, Ironside JW, DeArmond SJ, Tateishi J (1996) Diagnostic criteria for sporadic Creutzfeldt-Jakob disease. Arch Neurol 53:913-920.

Lamanda A, Zahn A, Roder D, Langen H (2004) Improved ruthenium II tris (bathophenantroline disulfonate) staining and destaining pro- 
tocol for a better signal-to-background ratio and improved baseline resolution. Proteomics 4:599-608.

Li KW, Hornshaw M, van der Schors RC, Watson R, Tate S, Casetta B, Jiminez CR, Gouwenberg Y, Gundelfinger ED, Smalla KH, Smit AB (2004) Proteomics analysis of rat brain postsynaptic density. J Biol Chem 279:987-1002.

Liu JP, Powell KA, Sudhof TC, Robinson PJ (1994) Dynamin-I is a $\mathrm{Ca}^{2+}$-sensitive phospholipid-binding protein with very high affinity for protein kinase C. J Biol Chem 269:21043-21050.

Lohmann C, Friauf E (1996) Distribution of the calcium-binding proteins parvalbumin and calretinin in the auditory brainstem of adult and developing rats. J Comp Neurol 367:90-109.

Marini AM, Strauss KI, Jacobowitz DM (1997) Calretinin-containing neurons in rat cerebellar granule cell cultures. Brain Res Bull 42:279-288.

Martin PR, McCool BA, Singleton CK (1995) Molecular genetics of transketolase in the pathogenesis of the Wernicke-Korsakoff syndrome. Metab Brain Dis 10:45-55.

Muller JMM, Rabouille C, Newman R, Shorter J, Freemont P, Schiavo G, Warren G, Shima DT (1999) An NSF function distinct from ATPase-dependent SNARE disassembly is essential for Golgi membrane fusion. Nat Cell Biol 1:335-340.

Nakano K, Kanai-Azuma M, Kanai Y, Moriyama K, Yazaki K, Hayashi Y, Kitamura N (2003) Cofilin phosphorylation and actin polymerization by NRK/NESK, a member of the germinal center kinase family. Exp Cell Res 287:219-227.

Paoletti F, Mocali A, Tombaccini D (1997) Cysteine proteinases are responsible for characteristic transketolase alterations in Alzheimer fibroblasts. J Cell Physiol 172:63-68.

Pavlov D, Muhlrad A, Cooper J, Wear M, Reisler E (2007) Actin filament severing by cofilin. J Mol Biol 365:1350-1358.

Pietrogrande MC, Marchetti N, Dondi F, Righetti PG (2003) Spot overlapping in two-dimensional polyacrylamide gel electrophoresis maps: Relevance to proteomics. Electrophoresis 24:217-224.

Pollak D, Weitzdoerfer R, Yang YW, Prast H, Hoeger H, Lubec G (2005) Cerebellar protein expression in three different mouse strains and their relevance for motor performance. Neurochem Int 46:19-29.

Resibois A, Rogers JH (1992) Calretinin in rat brain: an immunohistochemical study. Neuroscience 46:101-134.

Schindler J, Lewandrowski U, Sickmann A, Friauf E, Nothwang HG (2006) Proteomic analysis of brain plasma membranes isolated by affinity two-phase partitioning. Mol Cell Proteomics 5:390-400.

Schindler J, Lewandrowski U, Sickmann A, Friauf E (2008) Aqueous polymer two-phase systems for the proteomic analysis of plasma membranes from minute brain samples. J Proteome Res 7: $432-442$.

Shin JB, Streijger F, Beynon A, Peters T, Gadzala L, McMillen D, Bystrom C, Van der Zee CEEM, Wallimann T, Gillespie PG (2007) Hair bundles are specialized for ATP delivery via creatine kinase. Neuron 53:371-386.

Steinacker P, Schwarz P, Reim K, Brechlin P, Jahn O, Kratzin H, Aitken A, Wiltfang J, Aguzzi A, Bahn E, Baxter HC, Brose N, Otto M (2005) Unchanged survival rates of 14-3-3 gamma knockout mice after inoculation with pathological prion protein. Mol Cell Biol 25:1339-1346.
Tardif E, Chiry O, Probst A, Magistretti PJ, Clarke S (2003) Patterns of calcium-binding proteins in human inferior colliculus: Identification of subdivisions and evidence for putative parallel systems. Neuroscience 116:1111-1121.

Thach WT, Bastian AJ (2004) Role of the cerebellum in the control and adaptation of gait in health and disease. Prog Brain Res 143: 353-366.

Tonge R, Shaw J, Middleton B, Rowlinson R, Rayner S, Young J, Pognan F, Hawkins E, Currie I, Davison M (2001) Validation and development of fluorescence two-dimensional differential gel electrophoresis proteomics technology. Proteomics 1:377-396.

Unlu M, Morgan ME, Minden JS (1997) Difference gel electrophoresis: a single-gel method for detecting changes in protein extracts. Electrophoresis 18:2071-2077.

Van den Bergh G, Arckens L (2004) Fluorescent two-dimensional difference gel electrophoresis unveils the potential of gel-based proteomics. Curr Opin Biotechnol 15:38-43.

Van den Bergh G, Clerens S, Firestein BL, Burnat K, Arckens L (2006) Development and plasticity-related changes in protein expression patterns in cat visual cortex: a fluorescent two-dimensional difference gel electrophoresis approach. Proteomics 6:3821-3832.

van Heusden GPH (2005) 14-3-3 Proteins: Regulators of numerous eukaryotic proteins. IUBMB Life 57:623-629.

Whiteheart SW, Schraw T, Matveeva EA (2001) N-ethylmaleimide sensitive factor [NSF] structure and function. Int Rev Cytol 207:71-112.

Wiltfang J, Otto M, Baxter HC, Bodemer M, Steinacker P, Bahn E, Zerr I, Kornhuber J, Kretzschmar HA, Poser S, Ruther E, Aitken A (1999) Isoform pattern of 14-3-3 proteins in the cerebrospinal fluid of patients with Creutzfeldt-Jakob disease. J Neurochem 73: 2485-2490.

Xu J, Kao SY, Lee FJS, Song WH, Jin LW, Yankner BA (2002a) Dopamine-dependent neurotoxicity of alpha-synuclein: A mechanism for selective neurodegeneration in Parkinson disease. Nat Med 8:600-606.

Xu ZP, Wawrousek EF, Piatigorsky J (2002b) Transketolase haploinsufficiency reduces adipose tissue and female fertility in mice. Mol Cell Biol 22:6142-6147.

Zettel ML, Frisina RD, Haider SEA, Oneill WE (1997) Age-related changes in calbindin D-28k and calretinin immunoreactivity in the inferior colliculus of $\mathrm{CBA} / \mathrm{CaJ}$ and $\mathrm{C} 57 \mathrm{BI} / 6$ mice. J Comp Neurol 386:92-110.

Zheng PP, Luider TM, Pieters R, Avezaat CJJ, Van Den Bent MJ, Smitt PAES, Kros JM (2003) Identification of tumor-related proteins by proteomic analysis of cerebrospinal fluid from patients with primary brain tumors. J Neuropathol Exp Neurol 62:855-862.

Zhu HP, Enaw JOE, Ma C, Shaw GM, Lammer EJ, Finnell RH (2007) Association between CFLI gene polymorphisms and spina bifida risk in a California population. BMC Med Genet 8:12.

\section{APPENDIX}

Supplementary data associated with this article can be found, in the online version, at doi: 10.1016/j.neuroscience.2008.02.017. 